\title{
Research on the Impact and Countermeasures of Cross-border E-commerce under the New-tax Reform
}

\author{
Dapeng Ren
}

Xi 'an Eurasia University, Xi 'an, Shaanxi, 710065

Keywords: Tax reform; Cross-border e-commerce; Impact; Coping strategies

\begin{abstract}
High-profile cross-border electricity business tax reform falls to the ground on April $8^{\text {th }}$, 2016, cross-border electricity pilot work over the past three years, will promote the standardization of the increasingly large cross-border electricity industry development. In general, tax reform will be accelerated the cross-border electricity industry matures, but also on each big companies in the industry a reshuffle, hit the pattern of the whole industry. Major cross-border import e-commerce enterprises have adopted strategies to cope with the tax reform. This paper mainly studies the impact and countermeasures of cross-border e-commerce under the new tax reform.
\end{abstract}

\section{Introduction}

Cross-border e-commerce plays an irreplaceable role in China's foreign trade and plays a powerful role in promoting China's economic development. In recent years, with the development of information technology, the coverage of the Internet and the progress of global trade integration, China's cross-border e-commerce has become a "dark horse" in China's foreign trade and is in rapid development. E-commerce has been applied to the business activities of cross-border trade, and has begun to take shape. This trade pattern has made a great contribution to the growth of China's import and export trade volume. However, with the rapid development of cross-border e-commerce, there are still some problems, such as the corresponding market supervision system, exchange settlement tariff and the construction of logistics enterprises. Therefore, it is necessary to take targeted measures to solve these problems as soon as possible while developing cross-border e-commerce.

For Hai Tao, act as purchasing agency such as cross-border electricity retail import taxes unfair problems in, cross-border electricity business tax implementation of the New Deal, the ministry of finance in our country with the general administration of customs, state administration of taxation issued documents, according to the formal implementation of cross-border e-commerce retail (enterprise to consumers, namely B2C) import tax policies, tax on cross-border e-commerce retail imported goods according to the goods, and synchronous adjustment by tax policy, cross-border electricity will use "cross-border electricity comprehensive tax" instead of "mail" tax, say goodbye to cross-border electricity duty-free era on the April 8th, 2016. There is no doubt that the domestic cross-border e-commerce industry has ushered in a round of reshuffle, and the detailed rules of the new tax policy for cross-border e-commerce also need to be improved. This paper mainly studies the impact and countermeasures of cross-border e-commerce under the new tax reform.

\section{Main contents of the New-tax Reform}

Cross-border e-commerce retail imported goods will no longer be subject to postal tax, but to customs duties, import VAT and consumption tax. With the implementation of the new tax policy for cross-border e-commerce, it marks the end of the pilot work of cross-border e-commerce over the past three years. Cross-border e-commerce will leave the previous "tax free era" and face the impact and pressure brought by the increase of tax burden cost.

The core content of the new policy focuses on: one is that the limit of individual single transaction is RMB 2,000, and the annual limit is RMB 20,000. Imported cross-border e-commerce retail imported goods within the limit are temporarily exempted from customs duties. The limit of 
single transaction is raised to RMB 2,000, and the annual limit of individual transaction is RMB 20,000. For cross-border e-commerce retail imported goods within the limits, the tariff rate shall be temporarily set at 0\%; Second, the VAT and consumption tax exemptions for import links will be abolished, which will be temporarily levied at $70 \%$ of the legal tax payable. Third, single transactions that exceed the single limit value, which exceed the individual annual limit value after accumulation, and single indivisible commodities whose customs value exceeds the limit value of 2,000 yuan are all taxed in full according to the general trade method.

\section{Impact of Cross-border e-commerce under the New-tax Reform}

In the view of enterprises, the most significant impact of the new round of tax reform is mainly concentrated in two aspects, namely the positive list system and the customs clearance system. Previously, the original pilot cities implemented the negative list system.

Changes in the new tax regime for cross-border e-commerce have little impact. But the subsequent regulatory changes, for companies, are very abrupt and take a very short time to adapt. The positive list was released on April 7, 2016 and officially implemented on April 8, 2016, with only a few hours to go. In the view of these enterprises, the advantage of cross-border e-commerce lies in its fast, new, abundant and abundant, which is also the shortcoming of traditional trade? The positive list directly affects the rich and abundant characteristics of e-commerce, and the market may become narrower. Customs clearance bills leave the goods in the bonded warehouse in a state of limbo. Because the supply channels of cross-border e-commerce enterprises are relatively complex and scattered, many of them are not directly supplied by manufacturers and cannot provide a series of qualifications such as certificates of origin required by customs clearance. Most goods do not enter customs, so they cannot be replenished

At present, the operation mode of domestic cross-border e-commerce platform mainly includes overseas purchasing platform mode, direct distribution/direct transport platform mode, self-operated B2C mode, self-operated direct purchase mode and overseas direct purchase mode. The cross-border e-commerce retail import tax reform has brought different impacts to different e-commerce platforms. Among them, the impact on cross-border e-commerce relying on bonded is obvious in the short term. The adjustment mainly has an impact on the price of "one low one high" products. In addition, if the unit price is higher than 2000 yuan, the tax cost will increase greatly. Under the influence of the new policy of cross-border e-commerce, the cross-border e-commerce enterprises of bonded import mode are faced with the problems of limited purchase of goods, order and decrease of output.

When interpreting the new policy, we should not only focus on the change of tax rate, but also pay attention to the different tax bases of cross-border e-commerce import (B2C) model and general trade import (B2B) model. The basis of general trade import is the transaction price of imported goods (generally lower than the retail price), while the basis of cross-border e-commerce import is the actual transaction price (including the retail price of goods, freight and insurance). The new policy reduces the tax burden gap between cross-border e-commerce import and general trade import. The policy adjustment will increase the cost of cross-border e-commerce with low threshold. The cost will be increased if the supply of goods continues to be prepared by purchasing on behalf of the buyer or by overseas retail stores. But to rich platform category and open price range is a positive. In the face of industrial changes, each cross-border e-commerce platform has its own response strategies, including adjusting its commodity structure and business structure.

Currently, the main modes of cross-border e-commerce industry are bonded mode and direct mail mode. In the short term, the impact of the adjustment on bonded cross-border e-commerce is obvious. E-commerce companies that rely entirely on the bonded goods mode face certain challenges and test periods. Those cross-border e-commerce enterprises that cannot make adjustments in time may face great growth pressure, and those that rely too heavily on capital may be eliminated. The new tax policy for cross-border e-commerce will lead to a decline in consumers' desire to buy and a shift of consumer demand to direct mail, while it will make no sense to take orders for tax exemption. After the tax reform, the original high tax rate goods will be affected by 
the decrease to $11.9 \%$ or $32.9 \%$, and gradually increase the proportion, e-commerce hot style will weaken, and the import sources of general trade will increase. Order limits have design flaws. Now that the annual quota and individual order quota are clearly defined, it is not reasonable to tax and manage in accordance with general trade to exclude single indivisible goods above 2,000 yuan from the cross-border electronic goods category system. At present, goods with a unit price of more than 2,000 yuan are mainly clothes, luggage, etc., accounting for about $20 \%$ of cross-border business, but the contribution to cross-border tax collection is up to $50 \%$. If the policy is tightened, it is easy to cause the loss of tax revenue generated by the recycling of consumption.

In the past, under the postal tax system, cross-border e-commerce companies paid much less tax than general trade. Even some loopholes in the tax exemption amount were also criticized as the gray industry of tax evasion. The unfair competition compared with general trade is not only between domestic regions, but also extends to domestic and foreign enterprises and leads to the reduction of national fiscal tax revenue. After the implementation of the new policy, the tax on cheap goods increased and the tax on expensive goods decreased, contributing to the improvement of product category richness. As the cost of relying on the bonded goods storage mode increases, the operation of hot style mode relying on low customer price will be affected, which will force the cross-border e-commerce platform to improve its full chain integration capability in logistics and supply chain organization.

\section{Specific strategies for Cross-border e-commerce to cope with the impact of tax reform under the New-tax Reform}

In the face of the new policy of importing cross-border e-commerce to be implemented, cross-border e-commerce platforms will take different approaches to deal with it, possibly passing on the increased tax cost to consumers, and possibly absorbing or driving down the supply price of overseas suppliers by themselves. Facing the pressure of price rise, large scale and powerful cross-border e-commerce players will rapidly adjust the supply chain mode and commodity structure, reduce the input and sales cost and strengthen the sales force, at the same time, improve the efficiency of supply chain circulation and enhance the upper bargaining power. With the implementation of the new tax policy, the competitive advantage of cross-border e-commerce platforms in the future lies in service and supply of goods, especially the requirements on platform services will be improved. In addition, diversified product types are also the development trend of cross-border e-commerce platforms in the future.

In the past three years and more, the cross-border e-commerce platform enjoyed the policy dividend, which has witnessed the rapid development stage, including the great development of Tmall international, Jumei, Netease koala, Jingdong global shopping and other large-scale e-commerce platforms, as well as the birth of honey bud baby, little red book, darling, and honey tao. After the new tax reform, major cross-border e-commerce platforms will face more competitors, and general traders will also participate in the import retail e-commerce. For example, wal-mart launched global e-purchase in its APP, aiming to join the cross-border e-commerce in China. Wal-mart with global purchasing advantage will have more opportunities than many cross-border e-commerce platforms in China. Faced with fair competition opportunities, major cross-border e-commerce platforms should make correct adjustments from the three aspects of users, logistics and supply chain to maintain the long-term and healthy development of themselves and the whole industry.

After solving the problems of supply chain, logistics and product authenticity, the next development goal of cross-border e-commerce is "scene marketing" to increase consumers' physical experience. During the "12-12" period, cross-border e-commerce platforms tried online scene marketing for the first time. "The offline life scenes will be integrated online, and the area will be divided through such life function scenes as dining room, living room, bedroom and baby room, and the theme venue of life experience scenes will be set with relevant commodities." Another e-commerce platform said that there are still many consumption scenarios that need to be expanded, such as buying bathtubs from overseas and realizing summer camp booking, medical examination 
in Japan and overseas medical treatment in the future. All major cross-border e-commerce companies have made the purchase of origin and overseas direct mail the most important part of this year's strategic layout.

We will strengthen the links between customs, commodity inspection, foreign control and national taxation, provide convenience for e-commerce enterprises engaged in cross-border trade, especially small and medium-sized enterprises, protect the development of industries, speed up customs clearance and inspection, and solve practical problems related to enterprise interests such as exchange settlement and tax refund. Second, international cooperation in cross-border e-commerce should be strengthened. In cross-border trade, overseas customers occupy a large proportion, electricity enterprises in cross-border trade activities also encountered some related to product quality supervision mechanism, express mail to cross-border e-commerce mode of inspection and quarantine and customs clearance service management system and so on related issues, therefore should strengthen the coordination between international cross-border e-commerce cooperation mechanism, promote the smooth development of cross-border electricity business enterprise in China.

\section{Conclusion}

To sum up, cross-border e-commerce is developing more and more rapidly along with the in-depth integration of China's economy and the world economy. The application of e-commerce in international trade has become an inevitable trend. For the cross-border e-commerce industry, 2016 was a year of gradually clearer policies, a year of big reshuffle, and a year of big outbreak of upgrading domestic consumption level. The new tax reform policy is a symbol of the standardization of cross-border e-commerce. On the one hand, it solves the "hukou" problem of cross-border e-commerce; on the other hand, it also promotes various platforms to think about their own advantages and cope with the tide of consumption upgrade. In order to better promote the development of Chinese cross-border electricity, perfect the market regulation mechanism, to promote logistics development is the top priority, the relevant functional departments should strengthen communication, increase the intensity of support, establish a good help to the development of cross-border trade market system and industrial facilities, believe in these favorable measures under the escort of cross-border e-commerce in our country there will always be a new leap forward.

\section{References}

[1] Yuting Wang. Impact of Cross-Border Tax Reform on Cross-Border Import E-Commerce Platform [J]. Northern Economy \& Trade, 2018(2):62-63

[2] Ying Liu, Houjian Zheng, Hongtao Tang. Impact and Countermeasures of Tax Reform on The Development of Cross-Border Import E-Commerce In China [J]. China Finance, 2016(23):50-51.

[3] Jie Cheng. Research on the Development Strategies Of Cross-Border Import E-Commerce in China Under the Background Of Tax Reform Policy [J]. China Management Informatization, 2016, 19(13):160-162.

[4] Jie Wang, Zhiming Zhao And Chen Chen. Development Trend and Adjustment Path Selection of China's Cross-Border E-Commerce Under The Tax Policy [J]. Foreign Economic and Trade Practice, 2017(6):37-40.

[5] Lei Wang. China's Cross-Border Import E-Commerce Model under the New Customs Tax Policy [J]. China Circulation Economy, 2017, 31(12):50-55. 